\title{
Construções parentéticas epistêmicas em perspectiva construcional
}

Sebastião Carlos Leite Gonçalves ${ }^{a}$

\begin{abstract}
Resumo
Investigo, neste artigo, construções parentéticas epistêmicas originadas de um esquema construcional formado por oração matriz com predicador adjetival e oração encaixada em posição argumental de sujeito. Assumindo os pressupostos teórico-metodológicos da Linguística Cognitivo-Funcional (CROFT, 2001; TRAUGOTT, 2008) e com base em dados de língua falada e escrita do português brasileiro contemporâneo, mostro que construções matrizes com predicadores adjetivais epistêmicos, ao se gramaticalizarem, passam a funcionar como construções parentéticas epistêmicas asseverativas focalizadoras. A identificação de níveis de esquematicidade das construções em análise ao mesmo tempo em que permite inferir um processo diacrônico de mudança de padrões construcionais lança pistas para a constituição de um quadro explanatório mais amplo acerca da formação e do funcionamento de construções parentéticas epistêmicas.
\end{abstract}

Palavras-chave: construcionalização; construções parentéticas epistêmicas; orações subjetivas. 


\section{Introdução ${ }^{1}$}

O fenômeno de que trato, neste artigo, toma como ponto de partida o complexo oracional composto de oração matriz com predicadores adjetivais e oração encaixada em posição argumental de sujeito, as chamadas orações subjetivas. Aliando os pressupostos teóricos da Gramática de Construções (CROFT, 2001, 2005) e a sistematização proposta por Traugott (2008) para tratar da gramaticalização de construções, foco minha análise em esquemas construcionais originados de orações matrizes com predicadores adjetivais que, ao se gramaticalizarem, passam a funcionar como construções parentéticas epistêmicas asseverativas focalizadoras, instanciadas pela representação esquemática mostrada em (1), em cujas ocorrências exemplificativas de (1a) a (1e) destaco, em sublinhado, a informação alvo da focalização, que, a depender da posição da construção, pode incidir sobre todo o conteúdo proposicional ou apenas parte dele. ${ }^{2}$

(1) $[(\text { SER })+\text { ADJ] }]_{\text {PARENTÉTICA EPISTÊMICA ASSEVERATIVA FOCALIZADORA }}$

\footnotetext{
Uma versão preliminar dos resultados desta investigação foi apresentada no XIX Seminário Nacional e VI Seminário Internacional do Grupo de Estudos "Discurso \& Gramática", que, realizados de 25 a 28 de novembro de 2014, no Instituto de Letras da UFF, tiveram por tema "Discurso \& Gramática em perspectiva construcional" Agradeço aos participantes pelas críticas e sugestões apresentadas ao trabalho naquela ocasião. Agradeço também aos pareceristas anônimos da revista pelas sugestões de melhoria do artigo.

2 Ao final de cada ocorrência, encontra-se indicado o corpus do qual ela foi extraída: Folha de São Paulo (FSP) e Amostra Censo do Projeto ALIP (AC), com indicação do número do inquérito e linha da ocorrência.
}

a. geralmente as lendas têm sempre... alguma coisa... de real de acontecido e depende é CLA::ro de cada narrador... fazer essa lenda... MAIS vistosa mais fantasiosa. (AC 146, L. 166)

b. Chama a atenção que a poeta Maria Gadú, nascida Mayra Corrêa Aygadoux, tenha encolhido seu complexo sobrenome francês para uma palavrinha tão simples que qualquer bebê pode balbuciar. De Aygadoux para Gadú fica mais fácil, é certo. (FSP, "Shimbalaiê" e "Tchubaruba" compõem gênero musical "criancês", 23/02/2011)

c. eu acho que o prefeito também tinha que ter em mente que ele tá administrando uma cidade... pro bem-estar da população e não pro BEM financeiro dele ou qualquer coisa desse tipo... acho que tem LÓgico uma realização -"ah:: eu sou prefeito de Mirassol"-... existe uma realização pessoal em falar isso... (AC 117, L. 454)

d. Boninho percebeu, óbvio, e vai trocar dois participantes neste domingo por um casal recém-chegado. (FSP, Afinal, quantos "BBBs" estão no ar 27/01/2011)

e. Aparentemente, Gallet foi esfaqueado e teve a bochecha esquerda arrancada por um tiro (Simenon também sabia ser macabro). É a vítima, evidente. Algumas páginas adiante, porém, descobriremos que era também um pequeno vigarista. (FSP, Tática: palavra proibida, 19/07/2011) 
Esse padrão construcional foi alvo de descrição e análise de Fortilli (2012) e de Fortilli e Gonçalves (2013), dentro do quadro teórico da gramaticalização e da dessentencialização de orações (HOPPER e TRAUGOTT, 2003; LEHMANN, 1988), não, portanto, sob uma abordagem construcional. Também sob a abordagem mais clássica da gramaticalização, vários outros autores já trataram de fenômeno semelhante envolvendo a gramaticalização de orações matrizes que adquirem status de advérbio ou de parentético epistêmico. Citem-se, a título de exemplo, para o PB, os trabalhos de Gonçalves (2003), sobre a gramaticalização dos verbos parecer, achar e crer, e os de Casseb-Galvão (1999; 2001), sobre a gramaticalização dos verbos achar e da construção diz-que, e, para o inglês, os trabalhos de Thompson e Mulac (1991), sobre a gramaticalização de I think, e o de Traugott e Dasher (2002), sobre a gramaticalização da construção I promisse.

Meu objetivo, neste artigo, é, portanto, oferecer uma reinterpretação de trabalhos meus e de Fortilli (FORTILLI, 2012; FORTILLI e GONÇALVES, 2013) à luz da perspectiva construcional, focalizando as mudanças que afetam orações matrizes com predicados adjetivais enquanto uma instância construcional, nos termos de Croft (2001), Bybee (2003), Traugott (2008), com vistas a alcançar os contextos específicos de uso que propiciam a mudança construcional e as motivações morfossintáticas, semânticas e pragmáticas que atuam na formação desse tipo específico de construções parentéticas epistêmicas no Português Brasileiro (PB).

Consoante o quadro teórico que embasa essa investigação, assumo aqui que as construções parentéticas epistêmicas mostradas em (1) constituem um pareamento de forma e sentido, alcançado por meio de um fortalecimento pragmático decorrente de um processo de crescente de (inter)subjetivização, rumo à marcação de atitudes subjetivas do falante em relação tanto a seu enunciado quanto a seu interlocutor, o que as tornam uma unidade de forma e sentido de certo modo diferente das construções matrizes das quais elas se originam, mais típicas de uma análise que consideraria tão somente suas partes constituintes.

Com o objetivo de verificar em que medida o fenômeno encontra-se espraiado no sistema da língua, a investigação empírica toma por base dados de fala e de escrita do PB con- 
3 Cf. original: "The recent literature on grammaticization seems to agree that it is not enou$\mathrm{gh}$ to define grammaticization as the process by which a lexical item become a grammatical morpheme, but rather it is important to say this process occurs in the context of a particular construction [...] In fact, it may be more accurate to say that a construction with particular lexical item in it becomes grammaticized, instead of saying that a lexical item becomes grammaticized." (BYBEE, 2003, p. 602)

4 Cf. original: "Roughly, a construction is an entrenched routine ('unit'), that is generally used in the speech community ('conventional'), and involves a pairing of form and meaning ('symbolic')" (CROFT, 2005, p. 274). temporâneo, o que pressupõe um tratamento sincrônico das construções objeto dessa investigação, mas que permite projetar uma trajetória de mudança no tempo à medida que se encontrem contempladas extensões contextuais de uso típicas de um processo de gramaticalização.

Feitas essas explanações gerais, este artigo segue estruturado nas seguintes partes: na seção (2.), apresento os aspectos teóricos relevantes e, na seção (3.), os aspectos metodológicos que embasam minha reinterpretação analítica do fenômeno em análise, a qual segue exposta na seção (4.), parte central deste artigo; na última seção, apresento as considerações finais.

\section{Aspectos teóricos}

Na última década, a pesquisa da mudança linguística via gramaticalização tem se voltado cada vez mais para uma perspectiva construcional, abandonando o clássico tratamento da gramaticalização de itens lexicais particulares. Já em Bybee (2003), encontra-se claramente advertência a esse respeito.

A literatura recente sobre gramaticalização parece concordar que não é suficiente definir gramaticalização como o processo por meio do qual itens lexicais tornam-se morfemas gramaticais, mas antes é importante dizer que esse processo ocorre no contexto de uma construção particular [...]. De fato, parece mais adequado dizer que uma construção com item lexical particular nela presente é que se torna gramaticalizada, ao invés de dizer que o item lexical é que se gramaticalizou. $^{3}$ (BYBEE, 2003, p. 602; grifos acrescidos)

Para a investigação de fenômenos de gramaticalização sob perspectiva construcional, é de fundamental importância a apropriação de conceitos e de metodologia coerentes com tal perspectiva. Recorrendo-se, então a trabalhos de linha cognitivista, encontra-se, em (2), o conceito de construção, basilar para este trabalho, fundamentado em Croft (2005), citado na sequência.

(2) Construção: unidade simbólica e convencional da gramática.

Grosso modo, uma construção é uma rotina consolidada ('uma unidade'), que é geralmente utilizada na comunidade de fala ('convencionalmente'), e que envolve um pareamento ("simbólico") de forma e significado. (CROFT, 2005, p. 274) 
É de Croft (2001) o esquema mostrado em (3), que, resumindo essa conceituação, explicita em que constituem os polos da forma e da função, que se encontram ligados, na construção, por um elo de correspondência simbólica.

(3) Modelo de estrutura simbólica de uma construção

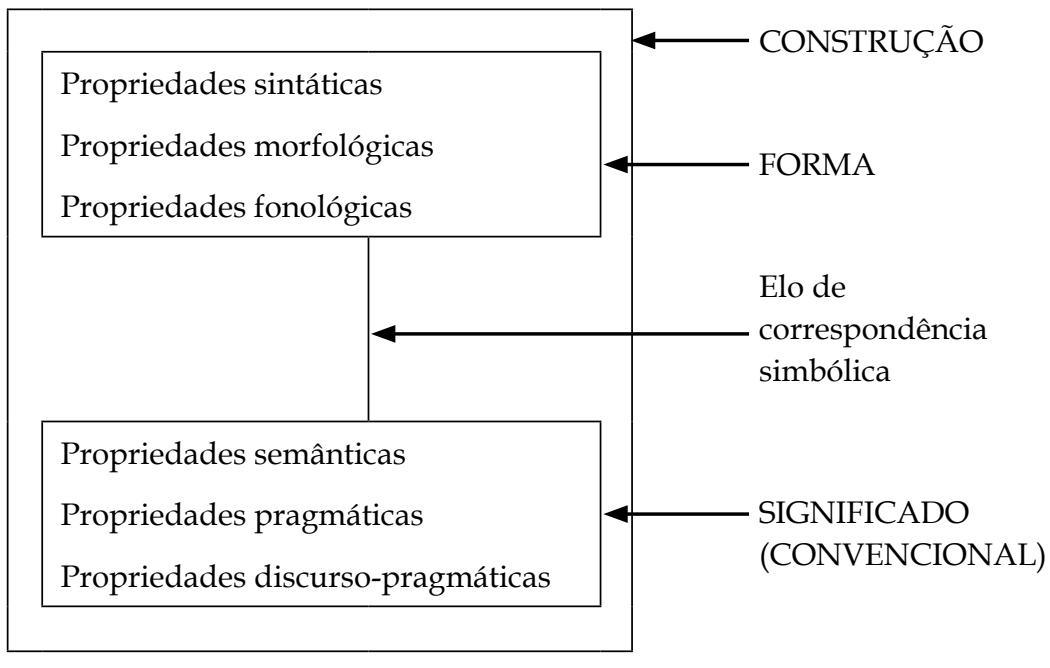

(CROFT, 2001, p. 18)

Segundo Traugott (2008), esse modelo de Croft permite explicar, em parte, a variação tipológica interlinguística, e, em parte, a gramaticalização, tratando-se, portanto, de um modelo mais adequado para abordar a gramaticalização de construção do que os modelos até então praticados.

Sem desconsiderar totalmente postulados advindos da abordagem mais clássica da gramaticalização, Traugott (2008c, apud TROUSDALE, 2012) emprega o termo construcionalização (gramatical), para se referir a processos de formação de novas construções na língua que servem a funções mais gramaticais ou procedurais, e a expressão mudança construcional, para se referir a aspectos de mudança, via gramaticalização, que podem afetar uma construção, quais sejam: (i) generalização, relacionada à esquematicidade da semântica de uma construção, ou seja, ao aumento de sua polissemia; (ii) produtividade, relacionada à habilidade de uma construção para atrair construções menos esquemáticas; (iii) composicionalidade, que visa verificar em que medida o significado de uma construção é derivável de suas partes componentes. Pautada por esses as- 
pectos de mudança que podem afetar uma construção, a autora propõe diferentes tipos de níveis construcionais em que tais mudanças podem ocorrer, os quais seguem expostos em (4).

(4) Tipos de nível construcional

"- macroconstruções: pareamento de forma-significado, definidos pela estrutura e pela função, como, por exemplo, partitivo, construção modificadora de grau etc,

- mesoconstruções: conjuntos de construções específicas de comportamento similar,

- microconstruções: Tipos de construção individuais

- construtos: ocorrências empiricamente atestadas, que são o lócus da mudança."

(TRAUGOTT, 2008, p. 236)

De acordo com esses níveis construcionais, o primeiro deles, o das macroconstruções, dá conta de construções esquemáticas altamente abstratas e, por isso, pouco propícias à atração semântica de outras construções; o segundo nível, o das mesoconstruções, agrupa microconstruções que partilham características do ponto de vista semântico e sintático, razão pela qual já pode atrair novas construções, por processo de analogia, tornando-as gramaticalizadas; o terceiro nível, o das microconstruções, reporta-se a tipos de construções individuais, que, alinhadas a um determinado conjunto de mesoconstruções, mantém suas idiossincrasias, no que diz respeito à forma e ao sentido, por conta de itens específicos recrutados na sua formação; e, o último nível, o dos construtos,

5 Cf. original:

- macro-constructions: meaning-form pairings that are defined by structure and function, e.g., Partitive, or Degree Modifier Constructions, etc.,

- meso-constructions: sets of similarlybehaving specific constructions,

- micro-constructions: individual constructiontypes,

constructs: the empirically attested tokens, which are the locus of change." é o lugar de representação de instâncias de uso, de fala ou de escrita, responsável por qualquer tipo de inovação.

Com base nos modelos de Croft (2001) e de Traugott (2008), torna-se possível advogar aqui pela natureza "convencional" das construções parentéticas epistêmicas focalizadoras mostradas em (1), a partir de evidências, a serem mostradas, de que se trata de unidades consolidadas e rotineiras da língua, envolvendo um sistema simbólico de pareamento entre forma e significado. Assim, em acordo com esse alinhamento teórico, mostro no quadro 1, a seguir, a representação do fenômeno a ser analisado, distribuído nos três níveis esquematização proposto por Traugott (2008). 
Quadro 1: Níveis de esquematização de construções parentéticas epistêmicas asseverativas focalizadoras do PB.

\begin{tabular}{|c|c|c|c|}
\hline NÍVEL & \multicolumn{3}{|c|}{ Tipo de construção } \\
\hline MACRO- & \multicolumn{3}{|c|}{$\begin{array}{l}\text { [(VERBO SER+) ADJETIVO (+QUE) }]_{(\text {MATRIZ)/(PARENTÉTICA) EPISTÊMICA }} \\
\begin{array}{r}\text { ASSEVERATIVA FOCALIZADORA } \\
(\ldots)=\text { CONSTITUINTES OPCIONAIS } \\
/=\text { FUNÇÕES MUTUAMENTE EXCLUSIVAS }\end{array}\end{array}$} \\
\hline MESO- & $\begin{array}{l}{[\text { ADJ+QUE] }]_{\text {MATRIZ }}} \\
\text { EPISTÊMICA ASSEVERATIVA } \\
\text { FOCALIZADORA } \\
\end{array}$ & $\begin{array}{l}\text { [SER+ ADJ] }]_{\text {PARENTÉTICA }} \\
\text { EPISTÊMICA ASSEVERATIVA } \\
\text { FOCALIZADORA } \\
\end{array}$ & $\begin{array}{l}{[\text { ADJ] }]_{\text {PARENTÉTICA }}} \\
\text { EPISTÊMICA ASSEVERATIVA } \\
\text { FOCALIZADORA } \\
\end{array}$ \\
\hline MICRO- & $\begin{array}{l}\text { claro que, lógico } \\
\text { que }\end{array}$ & $\begin{array}{l}\text { é certo, é claro, é } \\
\text { evidente, é lógico }\end{array}$ & $\begin{array}{l}\text { certo, claro, evidente, } \\
\text { lógico, óbvio }\end{array}$ \\
\hline
\end{tabular}

O que deve ficar apreendido desse quadro 1 é que as três mesoconstruções representadas originam-se de uma mesma macroconstrução, com a diferença de que apenas as duas últimas representam instâncias mais gramaticalizadas ao adquirirem funções parentéticas que a primeira ainda não apresenta, embora todas as três sejam originadas num processo de gramaticalização de construções matrizes de natureza epistêmica asseverativa que tomam por complemento uma oração em posição argumental de sujeito. A rotinização dessas construções leva à redução do significado lexical dos itens que a compõem, o que, por consequência, leva a um aumento de generalidade, tornando-a mais e mais esquemática e menos decomponível sintática e semanticamente, em razão da redução da estrutura sintática e da abstratização de significado (BYBEE, 2003).

\section{Aspectos metodológicos}

Os dados analisados nesta investigação provêm de dois diferentes corpora, um de fala e outro de escrita, a saber:

(i) amostras de fala do Projeto ALIP (Amostra Linguística do Interior Paulista), que, reunidas no Banco de dados Iboruna, registram a variedade do PB usada na região noroeste do Estado de São Paulo (GONÇALVES, 2007); 
(ii) textos escritos do caderno Ilustrada da versão online do jornal Folha de São Paulo (FSP), publicados no período de 01 de janeiro de 2009 a 30 de julho de 2011 (FORTILLI, 2012).

Nas análises iniciais, foram considerados dados de adjetivos que integram tanto construções matrizes encaixadoras de oração subjetiva como construções parentéticas epistêmicas, critério de seleção que levou à coleta de 616 ocorrências representativas dos diferentes padrões construcionais com predicados matrizes adjetivais que escopam uma oração. $\mathrm{Na}$ tabela 1, a seguir, apresento a distribuição da frequência, em números absolutos, de cada um dos esquemas construcionais considerados no levantamento dos dados.

Tabela 1 - Frequência de esquemas construcionais nos corpora investigados.

\begin{tabular}{|c|c|c|c|}
\hline \multirow{2}{*}{ Esquemas construcionais } & \multicolumn{2}{|c|}{ Modalidade } & \multirow{2}{*}{ Total } \\
\hline & Falada & Escrita & \\
\hline$I-[(V E R B O S E R)+A D J E T I V O]_{\text {MATRIZ NÃO-EPISTÊMICA }}$ & 104 & 206 & 310 \\
\hline$I I-\left[V E R B O S E R+\right.$ ADJETIVO $_{\text {MATRIZ }}+[Q U E]$ & 41 & 29 & 70 \\
\hline $\begin{array}{l}\text { III - }[(\text { SER }+) \text { ADJ }(+Q U E)]_{(\text {MATRIZ)/(PARENTÉtICA) }} \\
\text { EPISTÊMICA ASSEVERATIVA FOCALIZADORA }\end{array}$ & 63 & 173 & 236 \\
\hline Total & 208 & 408 & 616 \\
\hline
\end{tabular}

Em razão do tipo de mudança construcional que pretendo enfocar, não estão sendo considerados nesta análise casos de construções matrizes formadas por predicados adjetivais que não sejam de natureza epistêmica (tipo I, da tabela 1), tendo em vista que tais tipos semânticos não chegam a alcançar o estatuto de parentéticos epistêmicos, dado padrão construcional que integram, como mostrado em (5), a seguir. Neste e nos demais casos, para maior clareza, abaixo do padrão construcional em análise, reproduzo, da Tabela 1, a frequência de sua ocorrência (em números absolutos) nos corpora investigados, e abaixo de cada ocorrência exemplificativa, seguem os tipos de

6 Essa classificação semântica é baseada em Gonçalves et al. (2008). predicado encontrados para cada uma das classes semânticas consideradas. $^{6}$ 
(5) Padrão de construções matrizes não considerados na análise $[(\text { VERBO SER })+\text { ADJETIVO] }]_{\text {MATRIZ NÃO-EPISTÊMICA }}$

Total de construtos nesse padrão: 104 (fala) e 206 (escrita) $=310$

a. Muito bom fazer churrasco lá (AC 35, L. 320)

$\rightarrow$ predicados avaliativos: bom, complicado, difícil-1, fácil, incrivel, importante, interessante, melhor, ruim.

b. Engraçado essa palavra estar tão em voga no programa. Ela é usada por sujeitos que decidem, do alto da pretensão que lhes cabe, formar um paredão só de homens para a final. (FSP, Nina Lemos: Correção política de vitrine não engana ninguém, 12/03/2011)

$\rightarrow$ predicados de atitude emocional: agradável, engraçado, gostoso, horrível, triste.

c. Victoria Beckham publicou neste domingo no Twitter a primeira foto de sua filha recém-nascida, Harper Seven, na qual é possível ver o pai, o jogador de futebol David Beckham, embalando o bebê. (FSP, Victoria Beckham posta no Twitter $1^{a}$ foto de sua filha Harper Seven, 17/07/2011)

$\rightarrow$ predicados deônticos: impossível, necessário, permitido, preciso, proibido, possível-1.

d. Limpar banheiro TODO dia... é sagrado (AC 32, L. 1341)

$\rightarrow$ predicados de frequência: comum, difícil-2, sagrado.

Observe-se que, pelo padrão construcional exposto em (5), o máximo de alteração que se verifica na construção matriz é a redução da cópula, como mostram as ocorrências em (5a) e (5b). O encaixamento de oração infinitiva é propriedade que restringe o funcionamento parentético da construção matriz, em razão de a oração infinitiva não se sustentar como construção independente, a exemplo de orações finitas, como se verá mais adiante. Deve-se ter claro, entretanto, que a possibilidade de construções matrizes desse padrão ocorrerem posposta à oração infinitiva, como mostra $(5 \mathrm{~d})$, não configura usos parentéticos.

Passo, então, à análise dos contextos de formação das mesoconstruções (tipo III, da tabela 1), com foco nas instâncias mais gramaticalizadas, iniciando a discussão na consideração do nível primário de esquematicidade (tipo II, da tabela 1). 


\section{De orações matrizes a parentéticos epistêmicos}

Interessa-me, inicialmente, tratar dos casos de construções matrizes adjetivais de orações subjetivas que apresentam, num nível primário de organização sintagmática (tipo II, da tabela 1), a esquematização mostrada em (6), com ocorrências exemplificativas de (6a) a (6e).

(6) nível primário de esquematização

$$
[\text { VERBO SER + ADJETIVO] }]_{\text {MATRIZ }}+[Q U E]
$$

Total de construtos nesse padrão: 41 (fala) e 29 (escrita) = 70

a. é engraçado que depois... quando nós éramos pequenos... o meu pai... se esqueceu do tanto que ele era arteiro e levado (AC 82, L. 199)

$\rightarrow$ predicado de atitude emocional: engraçado.

b. é bom que você tenha assim essa opinião formada (AC 36, L. 367)

$\rightarrow$ predicados avaliativos: normal-1, bom, interessante.

c. É preciso, aqui, que se explique que os filmes produzidos por grandes estúdios, como Warner e Fox, são lançados por essas mesmas companhias. (FSP, Mercado de filmes tem reação após crise, 18/02/2011)

$\rightarrow$ predicado deôntico: preciso.

d. É claro que tem aquelas pessoas que sabem aproveitar (AC 22, L. 563)

$\rightarrow$ predicados epistêmicos: certo, claro, evidente, lógico, possível, provável.

e. Mas, espera, não é normal que as pessoas namorem, beijem, fiquem? (FSP, Por que Justin Bieber e Luan Santana não podem ter namorada, 21/09/2010)

$\rightarrow$ predicado de frequência: normal-2.

Nesse primeiro nível de esquematização mostrado em (6), integram esse padrão construcional predicados matrizes de classes semânticas variadas, a saber: de atitude emocional (6a), avaliativo (6b), deôntico (6c), epistêmico (6d) e de frequência (6e). Observe-se, a esse respeito, que a classe dos epistêmicos é a que comporta um número maior de tipos específicos de 
predicados, seis no total (certo, claro, evidente, lógico, possível e provável), já um primeiro indício da participação mais efetiva dessa classe de predicados nesse padrão construcional de nível primário, que corresponde a uma organização sintagmática em torno da qual se observa uma clara relação de subordinação sentencial formada por uma construção matriz, composta de cópula e de predicador adjetival, na qual, por meio do complementizador que, se encaixa em posição argumental uma oração finita, sobre cujo conteúdo incide algum tipo de qualificação do enunciador (que se estende do certo ao provável), a partir do ponto de vista argumentativo que assume perante seu enunciado e seu interlocutor.

Considerando-se essa participação mais acentuada de predicados epistêmicos na composição das construções matrizes, o padrão construcional mostrado em (6) vai se tornando mais e mais esquemático, à medida que, pela frequência de uso, é possível reanalisar o complementizador que não mais como parte integrante da oração encaixada, mas como parte de um padrão construcional emergente, do tipo mostrado em (7), cuja construção matriz se especializa na codificação de modalidade epistêmica, em geral.

(7) Padrão construcional emergente: construcionalização

$$
[\text { VERBO SER + ADJETIVO + QUE }]_{\text {MATRIZ EPISTÊMICA }}
$$

Para esse padrão emergente, estou considerando a sequência formada por [VERBO SER + ADJETIVO + QUE] como uma construção, porque é esse o ambiente alvo da mudança construcional enfocada aqui, e não a segmentação tradicional mostrada em (6), em que a conjunção integrante compõe com a oração encaixada outra construção. Constitui, portanto, objeto primeiro de análise do processo de construcionalização a construção matriz desse padrão emergente, e secundariamente, propriedades da construção representada pela oração encaixada, apenas para a apreensão de como a interação entre elas desencadeia mudanças que afetam a construção matriz, mas não a oração que ela encaixa, como mostra a configuração do novo padrão construcional em (8), o qual propicia, por meio de em um nível intermediário de mudança (como mostram 
(8a) a (8c)), a formação de construções parentéticas epistêmicas asseverativas focalizadoras (como mostram (8d) a (8i)).

(8) Novo padrão constructional: mudança construcional

[(SER+) ADJ (+QUE)] (MATRIZ) / (PARENTÉTICA) EPISTÊMICA ASSEVERATIVA FOCALIZADORA

(...) = CONSTITUINTES/FUNÇÕES OPCIONAIS

/ = FUNÇÕES MUTUAMENTE EXCLUSIVAS

Total geral de construtos: $236=63$ (fala) e 173 (escrita)

Padrão de nível intermediário

[ ADJ + QUE $]_{\text {MATRIZ EPISTÊMICA ASSEVERATIVA FOCALIZADORA }}$

Total de construtos: $34=24$ (fala) e 10 (escrita) (somente lógico e claro)

a. Claro que o meio/fim dos anos 1960, com Beatles, Stones, Beach Boys, Who, Kinks, Dylan e tantos outros, ainda é imbatível em termos de inventividade. (FSP, Interseção entre rock e pop. 02/05/2011)

b. se as pessoas temer a Deus se as pessoas... conhecer a vontade do Senhor... CLAro que o mundo não estaria como está....(AC 142, L. 170)

c. LÓgico que Deus escuta o que a gente pede (AC 51, 489)

\section{Construções parentéticas epistêmicas asseverativas focalizadoras}

$[(\mathrm{SER}+) \text { ADJ }]_{\text {PARENTÉTICA EPISTÊMICA ASSEVERATIVA FOCALIZADORA }}$

Total de construtos: 182 = 39 (fala) e 163 (escrita)

d. Inf: roubaram uma égua aqui óh

Doc.: é lógico ... eles investigaram né? (AC 63, L. 1145)

e. Afora isso houve, é claro, a apresentação dos participantes. (FSP, Renato Kramer: Refazenda, 20/07/2011)

f. Chama a atenção que a poeta Maria Gadú, nascida Mayra Corrêa Aygadoux, tenha encolhido seu complexo sobrenome francês para uma palavrinha tão simples que qualquer bebê pode balbuciar. De Aygadoux para Gadú fica mais fácil, é certo. (FSP, "Shimbalaiê" e "Tchubaruba" compõem gênero musical "criancês", 23/02/2011)

g. Certo, a realidade sempre foi mais complexa do que a nossa apreensão dela. (FSP, Amor por política e leitura, 29/06/2009) 
h. As duas exceções, lógico, estão no álbum recém-lançado. James Taylor aparece com "Carolina in My Mind", amostra do bitter sweet pop que consolidaria nos anos 1970 ao lado de nomes como Carly Simon e Jim Croce. (FSP, Coletânea reúne artistas, 18/06/2011)

i. falamos "óh L. aconteceu isso isso e isso né?... nós fomos no Sarau... o teu noivo tava lá" -... aí ela ficou super furiosa... CLA::ro (AC 70, L. 110)

Diferentemente do padrão construcional de nível primário mostrado em (6), que conta com microconstruções variadas, representadas por predicados matrizes de diferentes classes semânticas, o novo padrão construcional mostrado em (8) restringe-se a microconstruções compostas apenas por predicados adjetivais de natureza epistêmica asseverativa, com função também de focalizador. Na representação desse padrão construcional, como indicado, constituintes encerrados entre parênteses são opcionais, e o funcionamento da construção como matriz ou como parentética é mutuamente exclusivo.

Sob esse padrão mais esquemático dado em (8), ocorrem nos dois corpora investigados 236 construtos que, conforme tabela 2, dada a seguir, distribuem-se em dois subesquemas construcionais, um que conserva a função estrutural de matriz e outro que suplanta essa função em favor de um funcionamento parentético.

Tabela 2 - Frequência de subesquemas do padrão construcional [(SER+) ADJ (+QUE)] (MATRIZ) / (PARENTÉtICA) EPISTÊMICA ASSEVERATIVA FOCALIZADORA*

\begin{tabular}{|c|c|c|c|}
\hline \multirow{2}{*}{ Subesquemas construcionais } & \multicolumn{2}{|c|}{ Modalidade } & \multirow{2}{*}{ Total } \\
\hline & Falada & Escrita & \\
\hline$[A D J+Q U E]_{\text {MATRIZ EPISTEMMICA ASSEVERATIVA FOCALIZADORA }}$ & 24 & 10 & 34 \\
\hline$[(S E R+) \text { ADJ] }]_{\text {PARENTÉTICA EPISTÊMICA ASSEVERATIVA FOCALIZADORA }}$ & 39 & 163 & 202 \\
\hline Total & 63 & 173 & 236 \\
\hline
\end{tabular}

$\mathrm{Na}$ distribuição dos dois subesquemas construcionais mostrados nesta tabela 2, é importante destacar a participação acentuada de dois dos cinco tipos de predicados adjetivais epistêmicos. Das 63 ocorrências do corpus de língua falada, 41 
delas são formadas pelo predicado lógico e, as 22 restantes, pelo predicado claro, enquanto as 173 ocorrências da modalidade escrita são formadas preponderantemente pelo predicado claro (136 ocorrências) e as outras 37, por outros tipos de predicados epistêmicos, como lógico, evidente, óbvio e certo.

Importante frisar que o pareamento forma/função identificado para esse novo padrão construcional remove dele a participação de predicados epistêmicos que não sejam asseverativos, como provável e possível, o que implica dizer que a função específica de epistêmico asseverativo é de fundamental importância para o reconhecimento também da função focalizadora de informação desse novo padrão construcional, indicando, assim, seu ganho em pragmática. Note-se, a esse respeito, que, a depender da posição que ocupa no interior do enunciado, além de modalizar, a construção também focaliza todo o conteúdo proposicional, quando ocorre no início ou fim de enunciado, de que (8a), (8b), (8c), (8d), (8f), (8g) e (8i) são exemplos, ou apenas parte dele, de que (8e) e (8h) são exemplos. Prototípicas do acúmulo dessas funções são construções em que ocorrem os predicados claro e lógico, os dois tipos de mais alta frequência, fato que contribui para cristalização desses construtos, permitindo, com isso, que, por processo analógico (HOPPER e TRAUGOTT, 2003), outros predicados epistêmicos asseverativos, como evidente, óbvio, certo, passem a compor construtos com a mesma função. Demonstra-se, assim, nos termos de Bybee (2003), a importância da frequência de uso, responsável pela formação de construções e pela incorporação de novos usos.

Ainda sobre o estatuto de focalizador dessas construções, observe-se que, em todas as ocorrências exemplificadas em (8), os conteúdos escopados (porção textual sublinhada) pelas respectivas construções constituem informações consideradas pelo locutor como conhecidas do interlocutor, ou ao menos inferíveis no contexto de interação, ficando clara certa busca de se promover a solidariedade no discurso, entendida por Witchmann et al. (2010) como de natureza eminentemente dialógica, uma vez que o que se procura é um certo compartilhamento de responsabilidade entre os interlocutores pelo conteúdo 
enunciado. Em outras palavras, o enunciador pressupõe que a informação focalizada é de conhecimento de seu interlocutor, que também a aceita como verdade. Brinton (1996 apud TRAUGOTT e DASHER, 2002), além de ver em casos semelhantes a esse, no inglês, marcas do falante para demonstrar que o conteúdo é um conhecimento compartilhado, menciona que tais construções marcam a saliência de uma parte da informação, justamente aquela que o enunciador julga ser conhecida de seu interlocutor. Essa marca de saliência fica clara nas ocorrências exemplificativas, em termos prosódicos, devido à função pragmática de focalização das construções, representada, na escrita, pelo recurso a vírgulas, e na fala, por pausas (reticências), alongamentos (dois pontos seguidos) e aumento de tessitura e ênfase (sílabas em caixa alta) envolvendo tais construções.

Por último, e não menos importante, a dispensabilidade da cópula nesse novo padrão construcional encontra explicação em dois expedientes morfossintáticos que perpassam todos os níveis contextuais: (a) nos dois corpora, sua ocorrência quase categórica em terceira pessoa do singular (3PS) e no presente do indicativo, formas não-marcadas flexionalmente; (b) o formato finito categórico da oração cujo conteúdo é escopado por construções de natureza epistêmica ( cf. (6)), revelando grau mínimo de dependência e de integração entre elas, nos termos de Lehmann (1988). Esses dois expedientes reforçam a ideia de que a avaliação por parte do enunciador acerca de um conteúdo proposicional ocorre sempre concomitantemente ao momento presente do ato de fala, não havendo, portanto, a necessidade de marcas temporais explícitas na construção, como já apontei, para os casos de outros parentéticos epistêmicos de base verbal, como parece, (eu) acho (eu) creio, que se cristalizam na forma de tempo de presente (GONÇALVES, 2003).

\section{À guisa de conclusão}

Feitas essas descrições, o esquema mostrado em (9), a seguir, tenta captar as extensões contextuais que propiciam a formação de construções parentéticas epistêmicas asseverativas focalizadoras. 
(9) Contextos de mudança na formação de construções parentéticas epistêmicas asseverativas focalizadoras

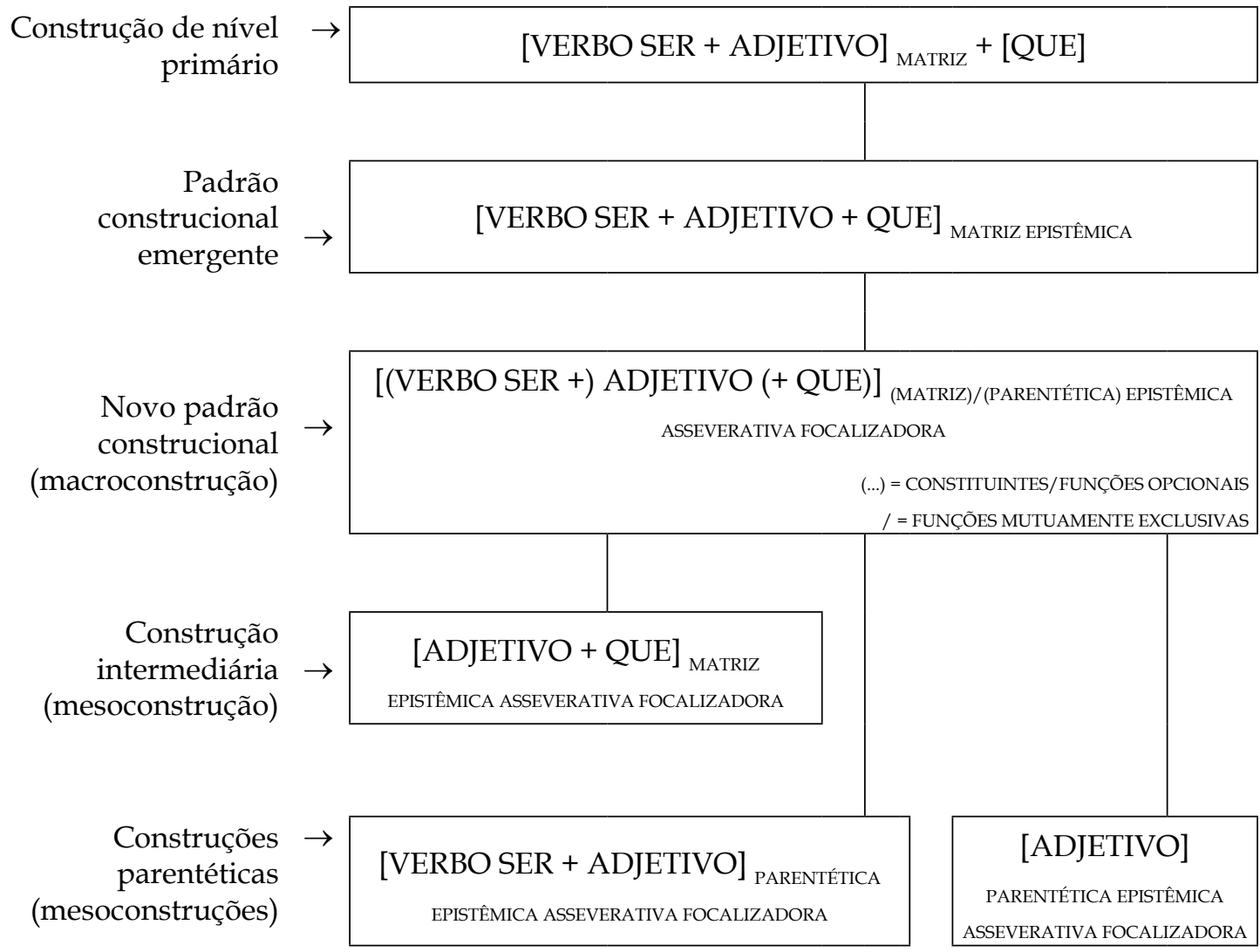

Explicitando o esquema em (9), tem-se que:

(i) construção do nível primário comporta na construção matriz uma gama de predicados de natureza semântica diferenciada, antecedidos de cópulas categoricamente flexionadas na 3PS do presente do indicativo e responsáveis por expressar algum tipo de qualificação do conteúdo da oração que ocorre encaixada na construção matriz por meio do complementizador que, marcando assim uma clara relação de subordinação dentro de um complexo oracional;

(ii) do nível primário para o padrão construcional emergente ocorre um processo de reanálise do complementizador que, o qual se integra à cons- 
trução matriz, agora restrita, em sua formação, à presença apenas de predicados epistêmicos antecedidos de cópula flexionada na 3PS do presente do indicativo. A construção matriz tem por função qualificar o conteúdo da oração encaixada como certo/provável, a partir da crença do enunciador acerca de um conteúdo proposicional por ele colocado à apreciação de seu interlocutor. É no âmbito da construção matriz que emerge um novo padrão construcional, o que implica já o reconhecimento da formação inicial de uma nova unidade de sentido e forma, não mais analisável pela simples soma de suas partes constituintes. Nesse nível, a presença do complementizador que integrado à construção matriz marca ainda uma relação de subordinação no complexo oracional envolvente;

(iii) o novo padrão construcional (surgido do padrão construcional emergente do nível anterior) confere às construções a função de focalizar um conteúdo proposicional, ou apenas parte dele, e de marcar a atitude asseverativa do falante em relação ao conteúdo focalizado. A relação entre a construção com função epistêmica asseverativa focalizadora e o conteúdo que ela escopa pode se dar por meio ainda de um processo de subordinação, marcado pela presença do complementizador que na construção matriz sem cópula, ou por um simples processo de modificação, caso em que construção com ou sem cópula alcança uma função parentética. Assim, esse novo padrão construcional licencia três tipos de construções: (a) uma construção intermediária mantendo ainda relação de subordinação entre uma construção encaixada a uma construção matriz sem cópula, nucleada por predicados epistêmicos asseverativos focalizadores; (b) duas construções parentéticas epistêmicas asseverativas focalizadoras, as quais, constituídas com ou sem cópula, perdem por completo o estatuto de subordinação, passando a atuar apenas como modificadoras de um conteúdo proposicional ou de apenas parte dele; 
(iv) a dispensabilidade da cópula nesse novo padrão construcional encontra explicação em sua ocorrência quase categórica na 3PS do presente do indicativo e no formato finito categórico da oração cujo conteúdo é escopado por construções de natureza epistêmica.

Com base nas extensões contextuais mostradas em (9), é possível inferir delas um processo diacrônico de mudança construcional, passo prospectivo para um entendimento mais aprofundado acerca das construções parentéticas epistêmicas asseverativas e não asseverativas, formadas não só por predicados adjetivais como também por predicados verbais integrantes de outros tipos construcionais, como (eu) acho, (eu) creio, parece etc, carentes ainda de investigação sob perspectiva construcional.

\section{REFERÊNCIAS BIBLIOGRÁFICAS}

BYBEE, J. Mechanisms of changes in grammaticization: the role of frequency. In: JOSEF, B.; JANDA, R. (eds.) The handbook of historical linguistics. Oxford: Blackwell Publishing, 2003, p. 602-623.

CASSEB-GALVÃO, V.C. O 'achar' no Português do Brasil: um caso de gramaticalização. 1999. 167f. Dissertação (Mestrado em Linguística) - Unicamp, Campinas.

Evidencialidade e gramaticalização no português do Brasil:

os usos da expressão diz que. 2001. 231f. Tese (Doutorado em Linguística) - Unesp, Araraquara.

CROFT, W. Radical Construction grammar: syntactic theory in ty pological perspective. Oxford: Oxford University Press, 2001. CROFT, W. Logical and typological arguments for Radical Construction Grammar. In: ÖSTMAN, J.; FRIED, M. (eds). Construction Grammars: Cognitive Grounding and Theoretical Extensions [Constructional Approaches to Language 3]. Amsterdam: John Benjamins, 2005, 273-314.

FORTILLI, S.C. Predicados matrizes adjetivais de orações subjetivas no português brasileiro: gramaticalização e dessentencialização. 2012. 163f. Tese (Doutorado em Estudos Linguísticos) - Unesp, São José do Rio Preto. 
FORTILLI, S.C., GONÇALVES, S.C.L. Gramaticalização da construção 'é claro que': padrões na fala e na escrita. Revista do GEL, São Paulo, v. 10, 2013, p. 80-103.

GONÇALVES, S.C.L. Gramaticalização, modalidade epistêmica e evidencialidade: um estudo de caso no português do Brasil. 250f. 2003. Tese (Doutorado em Linguística) - Unicamp, Campinas, 2003.

. Banco de dados Iboruna: amostras eletrônicas do português falado no interior paulista. 2007. Disponível em: http:://www. iboruna.ibilce.unesp.br. Acesso em out.2007.

GONÇALVES, S. C. L., SOUSA, G. C., CASSEB-GALVÃO, V. C. As construções subordinadas substantivas. In: ILARI, R., NEVES, M. H. M. (orgs.). Gramática do português falado culto no Brasil: classe de palavras e processos de construção. v.2. Campinas: Editora da Unicamp, 2008, p. 1021-1084.

HOPPER, P., TRAUGOTT, E. Grammaticalization. 2.ed. Cambridge: Cambridge University Press, 2003.

LEHMANN, C. Towards a typology of clause linkage. In: HAIMAN, J., THOMPSON, S. (eds.). Clause combining in grammar and discourse. Amsterdam/Philadelphia: John Benjamins, 1988, p. 275-330.

THOMPSON, S., MULAC. A. A quantitative perspective on the grammaticalization of epistemic parenteticals in English. In: E. Traugott, B. Heine. (orgs.). Approaches to grammaticalization. Vol. 1. Philadelphia: John Benjamins Publishing Company, 1991, p. 314-329

TRAUGOTT, E.C. Grammaticalization, constructions and the incremental development of language: Suggestions from the development of degree modifiers in English. In: ECKARDT, R.; JÄGER G.; VEENSTRA, T. (eds.). Variation, Selection, Development - Probing the Evolutionary Model of Language Change. Berlin/New York: Mouton de Gruyter, 2008, p. 219-250.

TRAUGOTT, E.C., DASHER, R. B. Regularity in semantic change. Cambridge: Cambridge University Press, 2002.

TROUSDALE, G. Grammaticalization, constructions and the grammaticalization of constructions. In: DAVIDSE, K. et al. (eds.). Grammaticalization and language change: new reflections. 2012, p. 167-198. 
WICHMANN, A., SIMON-VANDERBERGEN, A. M., AIJMER, $K$. How prosody reflects semantic change: A synchronic case study of of course. In: CUYCKENS, H., DAVIDSE, K., VANDELANOTTE, L. (ed.).Subjectification, intersubjectification and grammaticalization. Berlin: Walter de Gruyter, 2010. (Topics in English Linguistics, 66).

\section{Abstract \\ Epistemic parenthetical constructions on constructional perspective}

In this paper, I investigate epistemic parenthetical constructions originated from a constructional scheme formed by a matrix clause with adjectival epistemic predicator and an embedded clause in subject position. I assume the theoretical and methodological framework of Cognitive-Functional Linguistics (CROFT, 2001; TRAUGOTT, 2008). Based on spoken and writing language data of contemporary Brazilian Portuguese, I show that the matrix constructions which become grammaticalized function as focusing and asseverative epistemic parenthetical constructions. The identification of schematicity levels of the constructions, while it allows inferring a diachronic process of constructional change, it provides clues to the formation of a broader explanatory framework about the formation and functioning of epistemic parenthetical constructions.

Keywords: constructionalization; epistemic parenthetical constructions; subjective clauses. 